\title{
THE MIMETIC RESEMBLANCE OF FLIES OF THE GENUS SYSTROPUS TO WASPS
}

\section{By Charles T. Brues}

\section{Biological Laboratories, Harvard University}

Together with a few relatives the genus Systropus is of very different appearance from the other members of the family Bombyliidæ to which it belongs. The body is extremely elongated and the dense pile that generally covers the body in the other, more or less thick-set bombyliids is so greatly reduced that the flies appear almost bare.

During a recent visit to the Dutch East Indies, I was fortunate in taking with the net two species of this genus on the island of Sumatra. Having previously observed and collected one of our common North American species, Systropus macer Loew, I was at once struck by the very different color pattern of its Sumatran relatives. Also the latter appear to mimic entirely different types of wasps, suggesting that two independent lines of evolution have been active in developing widely divergent, but equally fine cases of mimetic resemblance in the two hemispheres. This situation appeared so remarkable, that I attempted to follow it further by an inquiry into the color patterns of the other numerous members of the genus which is known to be almost world-wide in distribution. On account of their striking appearance and easy recognition a great many species have been described by a considerable number of entomologists.

Bezzi, in his taxonomic review of Systropus has already commented on the general color pattern which prevails among the species inhabiting two of the great zoological regions. He refers to the Oriental forms as having the aspect of vespids and the Nearctic ones as ammophiloid, i.e., like the sphecoid genus "Ammophila" now called Sphex by taxonomists. The comparison is particularly apt in the case of the North American species as the resemblance to these digger-wasps is very great. Indeed, when in flight our com- 
mon Systropus macer Loew may be readily mistaken for a species of "Ammophila", but it has the habit, frequently seen in dipterous mimics of wasps and bees, of resting on the leaves of plants even during the brightest hours of sunshine.

Among the Oriental and Indomalayan species the resemblance to vespid wasps is not nearly so close, but nevertheless very striking. In the case of Systropus numeratus de Meijere of which I collected a male at Bangkinan, Sumatra, during May 1937, it would appear that the model is Stenogaster micans Sauss. ${ }^{1}$ as this wasp was flying very abundantly in the vicinity at the time the Systropus was taken. The two are of approximately the same size, but the gaster of the wasp is much stouter and the yellow markings on the thorax are larger, darker and do not coincide in size or position; likewise the wasp is brilliantly spotted on the sides of the gaster which is not the case in the fly. Nevertheless when alive the close resemblance is unmistakable although it is not borne out by a too critical comparison of the pinned specimens.

Another species, Systropus varipes Edwards, collected near Pematangsiantar, Sumatra is much smaller with darker legs and abdomen, and although quite wasp-like, is less conspicuously so and no vespids that resemble it at all closely were observed flying at the same time. Several of the small social species which are there common were present; all of these are much stouter and could not under any circumstances be confused with the Systropus.

In general, the species of Systropus in this part of the world are "vespoid" mainly by reason of a conspicuous spotting of the thorax which is marked with light yellow. Although the pattern varies, the basic arrangement of markings is of one type with permutations in shape and size. The coloration of the abdomen is black, varied with reddish brown or dull yellow, the reddish usually at the base and the yellow on the apical segments or venter.

In the Nearctic "ammophiloid" species the pale spotting of the thorax disappears and the reddish color is restricted to the petiolar basal segments of the abdomen while the

\footnotetext{
${ }^{1}$ Kindly identified for me by Dr. Jos. Bequaert.
} 
yellowish abdominal markings are lost. This coloration, in combination with the shape of the body produces the really astonishing resemblance between the fly and wasp, since most of our common "Ammophilas" have the conspicuous red basal abdominal marking.

The African species are in general colored like the Nearctic ones with the ferruginous color sometimes extending conspicuously on to the thorax, although pale spotted ones are known also from this continent.

Among the species known from the Neotropical region the thorax may be conspicuously marked with whitish or yellowish or this pale pattern may be almost entirely suppressed. They are thus intermediate between the "vespoid" and "ammophiloid" series.

A Tasmanian species, $S$. clavifemoratus Hardy is of the unspotted type and also one from Madagascar while $S$. studyi Enderlein from South China is said by its describer to resemble Ammophila atripes.

If then we consider the species from the several zoological regions together the development of two such divergent mimetic types is not so surprising for each appears to represent a modification of not such very great extent from a somewhat intermediate pattern. As the "ammophiloid" type is more widely distributed, extending even into the Australian region, we may consider the development of conspicuous yellowish spotting as the more recent pattern. 

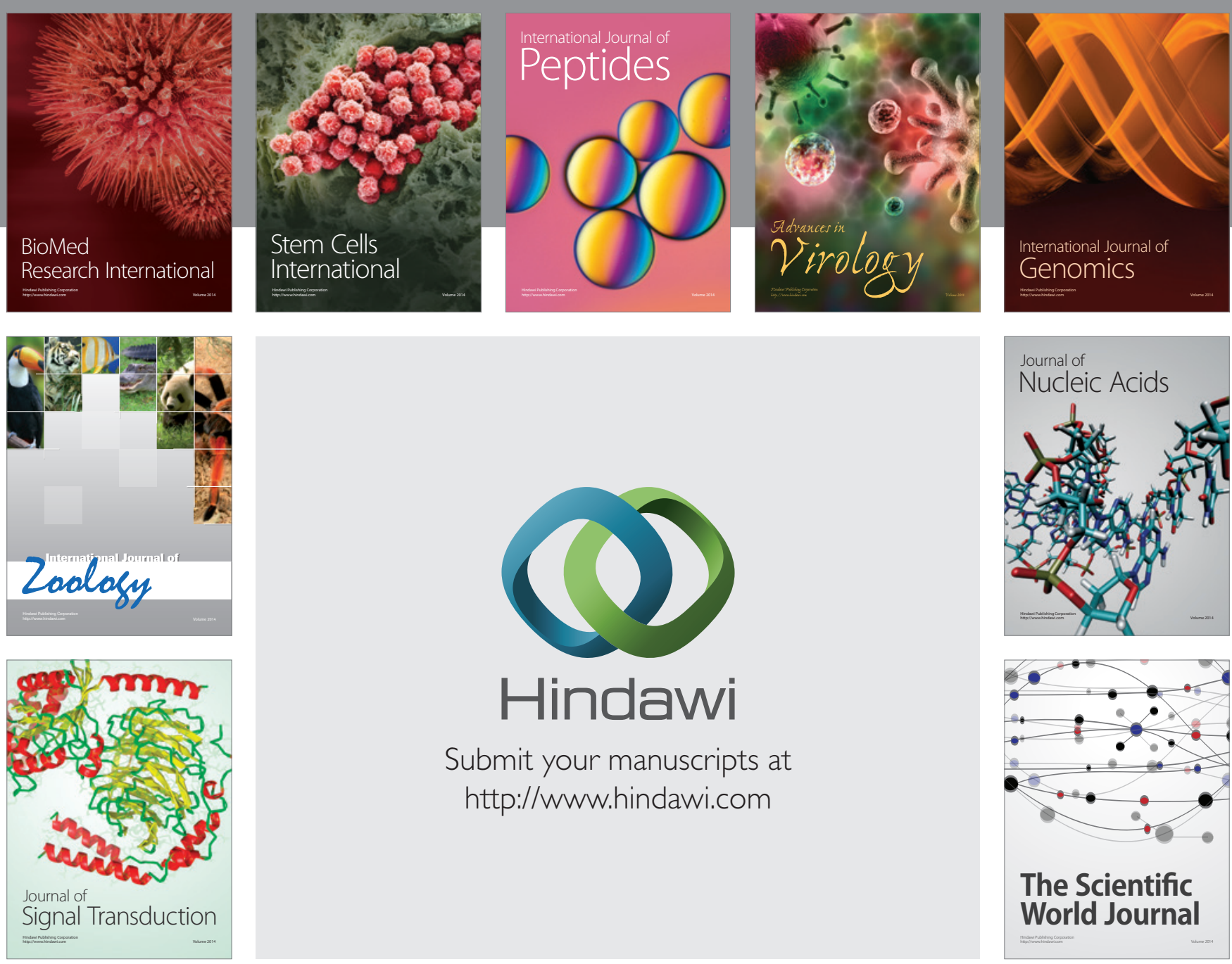

Submit your manuscripts at

http://www.hindawi.com
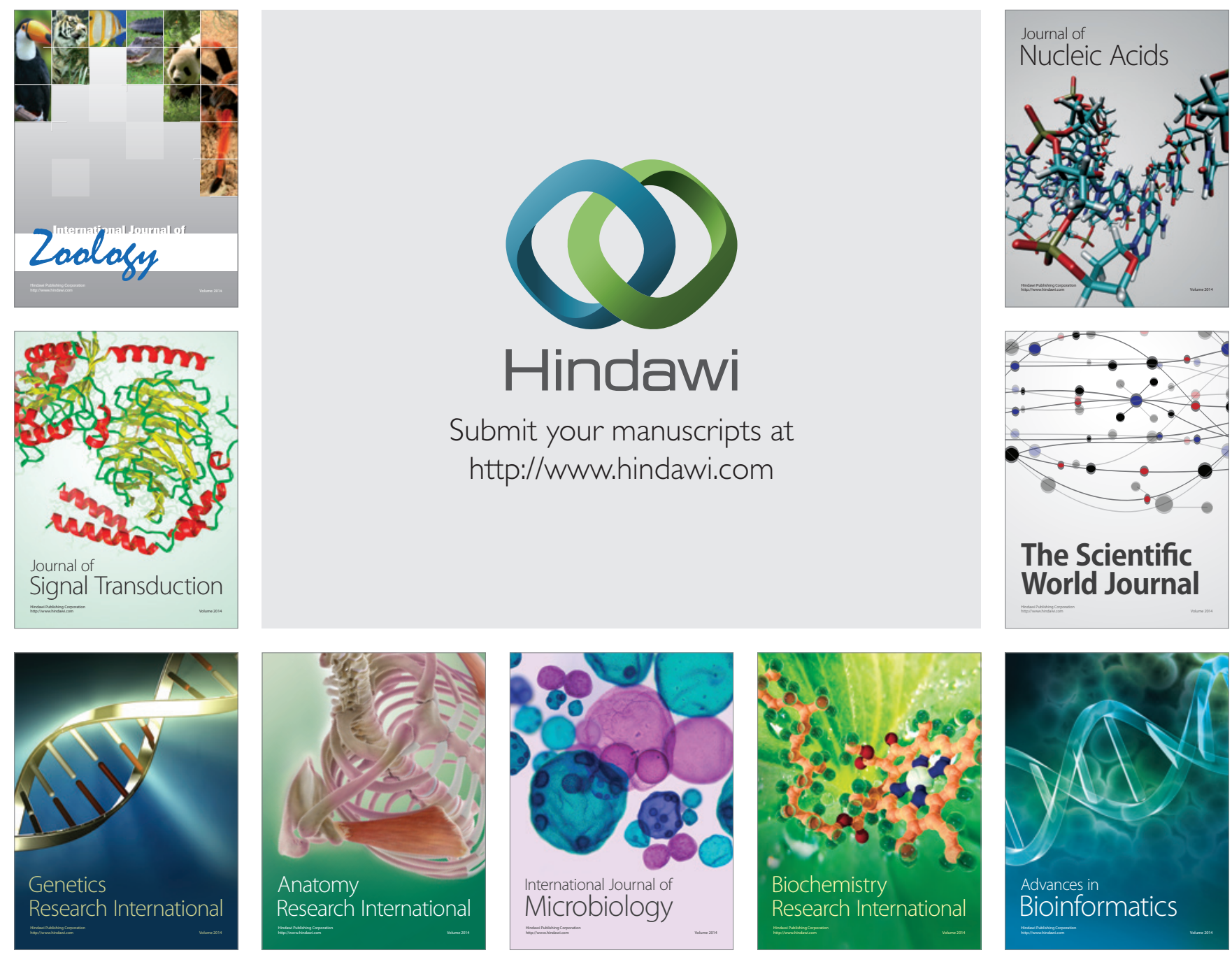

The Scientific World Journal
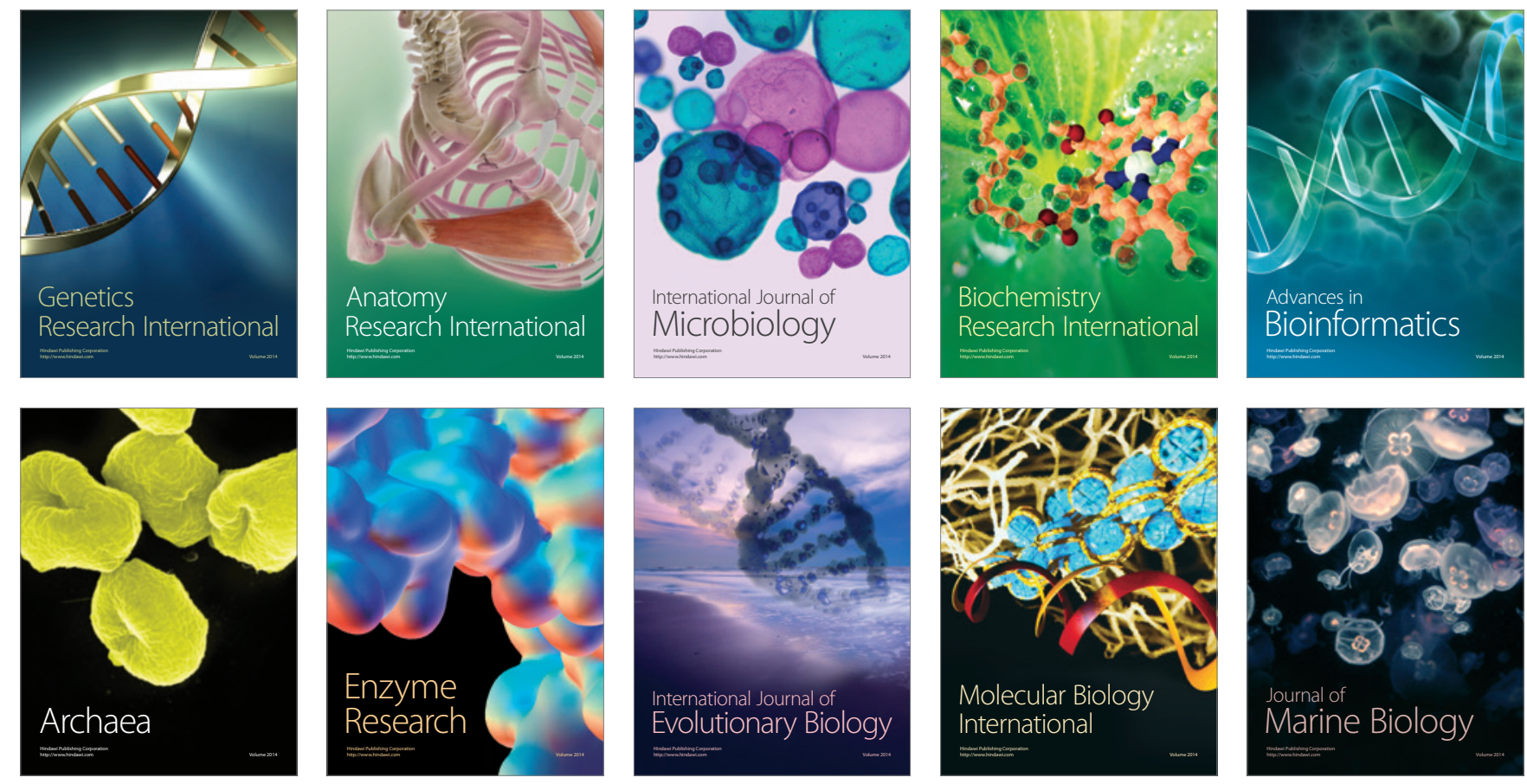